\title{
Einige Bemerkungen über die spezifische Therapie der Tuberkulose ${ }^{1}$.
}

\author{
Von \\ Dr. Kasimir Dluski, \\ Chefarzt der Heilanstalt für Lungenkranke in Zakopane.
}

Mit 2 Tabellen.

In unserer Arbeit „Über Tuberkulinanwendung in der Lungentuberkulose etc." (Brauers Beiträge Bd. X) versuchten wir eine Reihe von Fragen zu erörtern, welche mit der Tuberkulinbehandlung im Zusammenhang stehen und deren Lösung, angesichts einiger Widersprïche erforderlich war.

Trotz der steten Fortschritte der Bakteriologie und speziell der Immunitätslehre sin I diese Fragen unseres Erachtens bis jetzt noch nicht genügend aufgeklärt.

Wenn wir also die uns aus der zugänglichen Literatur bekannten Resultate neuer Forschungen wiedergeben, so werden wir auf unsere früheren Bemerkungen zurückgreifen und beide gemeinsam behandeln.

Auffallend ist vor allem die Zahl und Verschiedenheit der spezifischen Präparate. Abgesehen von der beträchtlichen Zahl der alten, gleichsam als Äste aus dem gemeinsamen Stamme T hervorsprossenden Präparate, welche den Organismus aktiv oder passiv immunisieren sollten, sind in den letzten Jahren wiederum nene Präparate auf der Bildfäche erschienen. Erwähnen will ich unter anderen das 'Tuberkulin Jacobs, die "Fiitrase" Haentjens und das IK von C. Spengler, welcher mit fast mathematischer Sicherheit die Wirkung dieses Prä-

1) Wir machen darauf aufmerksam, dass wir feruerhin das B e ranecksche Tuberkulin mit $\mathrm{TBK}$, das Kochsche Alttuberkulin mit $\mathrm{T}$, den menschlichen Tuberkelbazillus mit tbc, den Perlsuchtbazillus mit PTBC bezeichnen werden. 
parates berechnete und selbst in rorgeschrittensten Fällen menschlicher Tuberkulose glänzende Erfolge erzielte, während I, a n d m a n $n$ bewiesen hat, dass alle Kaninchen und Meerschweinchen trotz der immunisierenden Wirkung des IK innerhalb 20-24 Stunden eingegangen sind (35).

Neuerdings haben Weicker-Bandelier (69) und Roepke gezeigt, dass das IK gar keine spezifische Wirkung in der Tuberkulose ausübt. Nacb Roepke könnte das IK nur "mit physiologischer Kochsalzlösung auf gleiche Stufe gestellt werden" (49). Hand in Hand mit dieser Verschiedenheit geht wohl gegenwärtig, wie auch früher, eine völlige Willkürlichkeit in der Wahl der Präparate - ohne theoretische Begründung derselben. Auf der IV. Versammlung der Tuberkulose-Ärzte 1907, wo die spezifische Therapie Gegenstand einer erschöpfenden Diskussion war, hat diese Willkürlichkeit einen scharfen Ausdruck in dem Vortrage eines der wärmsten Anhänger Kochs, - Bandeliers - gefunden, welcher deutlich erklärte, „dass es weniger auf die Wahl des l'räparates, als auf die Methode der vorsichtig wägenden, individualisierenden Behandlung in der Hand des erfahrenen Tuberkulintherapeuten ankommt." Als Schluss, sagt er: "vielleicht führen fortgesetzte Arbeiten zu einer Indikation für die verschiedenen Tuberkuline“ (1).

Die Behauptung Bandeliers war auf jenem Kongress der Ausdruck der allgemeinen Ansicht von Spezialärzten mit langjähriger Erfahrung auf dem Gebiete der Tuberkulosebehandlung, was betont sei. Es ergibt sich aus diesem Satze, dass die Kochschen Präparate T, TR und $\mathrm{BE}$ (Bazillenemulsion), deren Wirkung nach $\mathrm{Koch}$ infolge verschiedener Zubereitungsweise grundverschieden ist, je nach dem Ermessen des Arztes verwendet werden können, sofern dies nur kunstgemäss geschieht ${ }^{1}$ ). Diese Willkür geht so weit, dass auf derselben Versammlung Petruschky sagen konnte: „ebensowenig wie jemand, der sich für Musik interessiert, gezwungen werden kann, Geige zu spielen und nicht ein anderes Instrument", ebensowenig wird man den Arzt zwingen, bei der Auswahl derjenigen Mittel, die "ihm sympathisch sind, nicht sein freies Ermessen walten zu lassen“. Somit ist für die Wirkung des Präparates nicht dessen eigene Substanz als solche, sondern die Anschauung des Arztes massgebend. Es würde dies vom Standpunkt der Tuberkulintheorie einen sonderbaren logischen Fehler bedeuten. - Wie wir nämlich unten sehen

1) Wir erinnern an die schon frïher von uns zitierten Worte Dieudonné's, dass das TR grundverschieden vom T ist und, nur den Namen und die Provenienz aus Tuberkelbazillenkulturen mit diesem gemein hat" ("Immunität, Schutzimpfung nnd Serumtherapie" 1905. 
werden, behauptet W olff - Ei s ner auf Grund seiner Theorie der Endotoxine und Bakteriolysine, dass hier kein Fehler vorliegt und dass die Ansicht Kochs fehlerhaft war, nach welcher die Präparate infolge ihrer Zubereitungsweise qualitativ different und dadurch auch ihre Wirkung auf den tuberkulösen Organismus eine rerschiedene sei. Nach Wolff-Eisner besitzen diese Präparate de facto einen gemeinsamen Grundbestandteil, wobei die Unterschiede zwischen T, TR und BE nicht qualitative, sondern nur quantitative seien. Wir werden uns mit dieser Frage noch befassen.

Zugleich mit dieser Willkür bei der Verwendung verschiedener Präparate des the ist noch der Mangel an festen Indikationen zur spezifischen Behandlung der Tuberkulose hervorzuheben. Diese Frage ist rom klinischen Standpunkte von eminenter Bedeutung.: Zurzeit herrschen noch unter den Anbängern Kochs selbst krasse Widersprüche. Auf die Einzelheiten will ich nicht eingehen, da sie früher veitläufig besprochen wurden; meine diesbezügJichen Bemerkungen halte ich auch fernerhin aufrecht.

Abgesehen von der erwähnten Willkür in der Wahl der Präparate und dem Fehlen präziser Indikationen, sehen wir zwei verschiedene Behandlungsmethoden einander gegenüberstehen: die alte $\mathrm{Kochsche}$ Methode, welche grosse Dosen des Mittels empfiehlt, um eine mehr oder weniger intensive Reaktion, als eine für den Organismus erwünschte Erscheinung hervorzurufen und die neue von Goetsch-Sahli, - in ihren Grundzügen von Anhängern Kochs, wie z. B. Bandelier und Roepke angenommene Methode (2), - welche mit minimalen Dosen operiert und den Zweck hat, die geringste Reaktion als für den Organismus unerwünscht, sogar gefährlich, zu vermeiden. - Nach den neuen Immunitätstheorien sollten diese Methoden für den biologischen Zustand der Zellen ganz verschiedene Folgen haben. Indessen erzielen die Anhänger dieser beiden entgegengesetzten Methoden - wiewohl dies paradox klingt - gleich gute Resultate, wenigstens nach ihren Statistiken zu urteilen. Im Zusammenhang mit diesen Widersprüchen auf dem Gebiete der Klinik, besteht eine ganze Reihe mehr oder weniger gewaltiger Widersprüche und Unklarheiten in Bezug auf die theoretischen Fragen; von denselben war bereits in unserer früheren Arbeit die Rede und sie werden uns auch jetzt beschäftigen, denn sie besitzen neben einer rein theoretischen, eine wichtige klinische Bedeutung.

Vor allem die mit dem Wesen des Tuberkelbazillus selbst zusammenhängenden Fragen. Bekannt ist die Theorie der "Übergangsformen" von L. Rabinowitsch, welche verschiedene Typen der Tuberkelbazillen, also der menschlicben-, der Rinder- und Vogel-Tuber- 
kulose in eine grosse Gruppe vereinigt. Bekannt sind ferner die Versuche von $\mathrm{Fe}$ istmantel, welche beweisen, dass eine ganze Reihe säurefester Bazillen, ja selbst Steptothrix Farcinica eine dem Tuberkulin ganz ähnliche Reaktion hervorrufen. Weiter sollen hier die bekannten Versuche über Immunisierung der Menschen gegen den menschlichen Bazillus mittels Rinderbazillus oder des Bazillus der Blindschleiche (C. Spengler, Klemperer und Mo eller) in Erinnerung gebracht werden, desgleichen eine ganze Reihe analoger Tierversuche. Alle diese Versuche haben deswegen eine klinische Bedeutung, weil die menschliche Tuberkulose bekanntlich nicht nur durch den Typus humanus, sondern durch den Typus bovinus, durch den Vogelbazillus usw. hervorgerufen wird. Aus diesem Grunde haben wir schon früher die Frage aufgeworfen, ob wir uns bei der spezifischen Behandlung stets solcher Präparate bedienen sollen, welche vom Typus humanus stammen. Diese Frage ist umso aktueller als manche hervorragende Kliniker larga manu, unter dem Einflusse C. Spenglers Präparate aus dem Typus bovinus verwenden. Allerdings wissen wir nicht, ob sie dabei die Grundsätze Spenglers befolgen, welcher bekanntlich behauptet, dass in $68 \%$ der Fälle menschlicher Tuberkulose ${ }^{1}$ ) zwei antagonistische Typen existieren, nämlich humanus und bovinus, und die spezifische Therapie auf antagonistischer Gegenwirkung beider Arten beruht ${ }^{2}$ ).

Wir wollen auf die Tatsache nicht eingeben, dass die theoretisch so wichtige Frage der Identität oder Nicht-Identität beider Typen bis vor kurzem trotz der Arbeiten genialer Forscher und ganzer Kommissionen, wie der deutschen und englischen noch unentschieden, ron C. Spengler im Sinne der Nicht-Identität. beider Typen für entschieden gehalten wird. Ja, was den typus humanus betrifft, gelangt Rothschild zu einer noch weiteren Differenzierung, indem er das Prinzip aufstellt, dass „wir eigentlich für jeden Kranken sein eigenes Tuberkulin herstellen müssten" (52). Er gebraucht ein aus dem im Sputum, Harn, oder anderen Exkreten enthaltenen Bazillen hergestelltes "Autotuberkulin"; fehlen diese Exkrete, so verwendet er "Universaltuberkulin", weches aus 5 verschiedenen Abarten des Typus humanus zubereitet wird. In dem letzten Fall „werden wir

1) „Die Doppelätiologie der tuberkulösen Phthise und die Vakzinationsbehandlung." Wien. klin. Rundschau 1906. Nr. 33.

2) Schröder kommt auf Grund seiner Untersuchungen $\mathrm{zu}$ folgenden Schlüssen: 1. Äusserst seltener Fund von den Perlsuchterregern identischen Bazillen bei der chronischen Lungentuberkulose des Menschen." 2. ,Die Grundlagen der Carl Spenglerschen Tuberkulintherapie beruhen auf falschen Voraus. sefzungen." (59). 
zwar, - nach Rothschild - der Forderung absolut spezifischer Autotuberkuline nicht gerecht - ihr aber doch näher kommen, als durch irgend eine der üblichen Anwendungstormen" (50). Die Ergebnisse solcher Behandlung mit den Resultaten des Kochschen Tuberkulins statistisch zusammengestellt, sprechen deutlich für die Rothschild sche Methode. Seine Schlussätze lauten folgendermassen: „jedenfalls bedeutet die Verwendung ron verschiedenen Kulturen derselben Barillenart einen entscheidenden Fortschritt zur Anregung wirklich spezifischer Schutzstoffe in unserem Organismus" (52).

Ausser den oben erörterten Fragen, die sowohl theoretisch als auch klinisch wichtig sind, bleiben noch wichtigere Fragen unentschieden, welche die ganze spezifische Behandlung der Tuberkulose beherrschen und die prinzipielle Grundlage der spezifischen Behandlung bilden sollten. Diese Grundlage ist endgültig noch nicht gefunden worden.

Es könnte manchem unsere Behauptung zu kühn erscheinen, aber angesichts der enormen Zahl von Arbeiten und Versuchen der letzten 2-3 Jahrzehnte, scheint uns die klinische Bilanz der spezifischen Behandlung verschiedener Infektionskrankheiten sehr dürftig zu sein. So sind z. B. die Erfolge der Behandlung verschiedener Formen der Streptokokkeninfektion mit den betreffenden Sera durchaus nicht sicher. Wolf-Eisner bezweifelt überhaupt den Wert des Streptokokkenserums (71). Ebenso steht es mit der selbst prophylaktischen Behandlung solcher Krankheiten wie Cholera und Typhus, obwohl hier die Statistik zugunsten der spezifischen bakteriologischen Präparate spricht. Dasselbe gilt für eine ganze Reihe anderer Krankheiten. Aber selbst bei der Anwendung der bekannten und in ihrer antitoxischen Wirkung mit beinahe mathematischer Genauigkeit bestimmten Sera, - des Diphtherie- und Tetanusserums - beobachten wir seltsame Gegensätze und paradoxe Erscheinungen. Das beim Menschen so sicher wirkende Diphtherieserum bewährt sich bei Tierversuchen nicht. Ganz entgegengesetzt rerhält sich das Tetanusserum, deren klinische Resultate Wolf-Eisner einfach als „ausserordentlich schlechte" bezeichnet (70).

Was soll man dann über die Tuberkulose sagen, deren Erreger äusserst komplizierte, bisher wissenschaftlich genügend nicht erklärte biologische Eigenschaften besitzt. Heute, nach der Entdeckung einer Reihe von Erscheinungen aus dem Gebiete der sogenannten Anaphylaxie, wird diese Frage noch komplizierter, wenn wir bedenken, dass zwischen der Wirkung verschiedener pflanzlicher und tierischer, giftiger und ungiftiger Eiweissstoffe ein bis jetzt unbekannter $\mathrm{Zu}$ - 
sammenhang bestehen soll und dass diese Wirkung durch ein biologisches uns auch unbekanntes Gesetz bestimmt wird.

Doch kehren wir zum Hauptthema zurïck.

Das Ziel der spezifischen Behandlung der Tuberkulose soll vor allem die Beseitigung ihrer Ursachen, also die Vernichtung des Bazillus und Beseitigung aller schädlichen Folgen des Bazillus aus dem Organismus sein. Die weitere Aufgabe beruht auf dem Schutz des Organismus vor erneuter Invasion der Bazillen, $d$. h. vor ,additioneller Infektion" oder vor "Reinfektion" — resp. "metastasierender Autoinfektion" - nach der v. Behringschen Terminologie. Mit anderen Worten: die Immunisierung gegen Tuberkulose soll eine Immunisierung gegen den Tuberkelbazillus sein.

Inwieweit sind nun die Grundlagen dazu gegeben? Schon aus den ersten Arbeiten $\mathrm{K}$ ochs geht deutlich hervor, dass der geniale Gelehrte in dem $\mathrm{T}$ kein die tbc. unmittelbar vernichtendes Mittel sieht, sondern demselben die Fähigkeit den Organismus gegen die Toxine des Tuberkelbazillus zu immunisieren, zuschreibt. „Es handelt sich also um eine reine Toxinimmunität, aber nicht um eine bakterielle" ${ }^{11}$. Aus diesem Grunde richtet er einige Jahre nach der Entdeckung des 'T sein ganzes Augenmerk auf Präparate, welche eben diese „bakterielle Immunisation" bewirken könnten. Wir wollen an dieser Stelle weder auf die Einzelheiten der Zubereitung von TR oder BE eingehen, noch auf die grossen Hoffnungen, welche $\mathrm{Koch}$ auf das Präparat TR gesetzt hat; über die Vollkommenheit des letzteren behauptet Koch, dass "weitere Verbesserungen des Präparates nicht mehr zu erwarten sind “2), obwohl er, vier Jahre später, dieser Behauptung entgegen, ein neues Präparat $\mathrm{BE}$ hergestellt hat, welches nach Bandelier viel wirksamer, als das TR sein soll, denn es enthalte alles, was an immunisierenden Substanzen in den Kulturen vorhanden ist, während das TR nur einen Bestandteil der Tuberkelbazillen enthält ${ }^{3}$ ).

Wir übergehen ferner eine ganze Reihe Gegensätze bei der klinischen Anwendung von T, TR oder BE durch Koch selbst, denn dieselben sind schon früher von uns ausführlich besprochen worden. Wir möchten nur zwei Tatsachen betonen. Erstens, dass die Präparate TR und BE, welche den Kranken gegen Tuberkelbazillus immunisieren sollen, selbst von den eifrigsten Anhängern Kochs bedeutend

1) R. Koch, „Über neue Tuberkulinpräparate“. Deutsche med. Wochenschr. 1897. Nr. 14.

2) Ibidem.

3) B a nd $\theta$ li er, „Über die Heilwirkung des Neutuberkulins (Bazillenemulsion). Zeitschr. f. Hygiene. Bd. 43. 1903. 
seltener als das ' $\mathrm{I}$ ' verwendet werden. Offenbar hat sich die von Koch theoretisch anfgebaute Immunisierung klinisch nicht verwirklicht. Zweitens liefert uns das heute in grossem Masse rerwendete $\mathrm{T}$ den Beweis für das, was von Koch vor Jahren deutlich betont wurde, indem er bemerkt: „Es kommt schliesslich zu einer vollkommenen Immunisierung gegen Tuberkulin, welche einige Monate anlualten kann. Auf die Tuberkelbazillen selbst hat die Immunisierung keinen Einfluss"1). Mit anderen Worten, man kann den menschlichen Organismus gegen hohe Dosen des verwendeten Präparates immunisieren. Die Praxis beweist - wie die neuen Forschungen ergeben dass man mittelst eines Präparates zugleich gegen grosse Dosen eines anderen allmählich immunisieren kann; wendet man z. B. allmählich $\mathrm{BE}$ an, so kann man nicht nur gegen $\mathrm{BE}$, sondern auch gegen $\mathrm{T}$ immunisieren.

Doch was beweist das? Nur, dass man den Organismus allmählich an grosse - bei der Methode von $\mathrm{S}$ a hli millionenmal grössere als die ursprünglichen - Dosen eines so zusammengesetzten Giftes, wie die rerschiedenen aus dem Tuberkelbazillus stammenden Tuberkuline gewöhnen kann. Aber eine solche Immunisierung gegen grosse Tuberkulindosen bedeutet noch keineswegs eine Immunität gegen den Iuberkelbazillus selbst. Was Koch vor 18 Jahren gesagt hat, wird in der letzten Zeit von Behring in seinen Tierversuchen und Wassermann in seinen Beobachtungen an Menschen bestätigt. Ersterer findet bei der Sektion des Rindes, bei welchem die Überempfindlichkeit gegen Tuberkulin bereits verschwunden war, „in der Lunge Knötchen mit käsigem Inhalt, mit und ohne Tuberkebazillen" 2). Der zweite stellt bei Menschen in dem Augenblicke, als sie die Fähigkeit gegen Tuberkulin zu reagieren infolge einer längeren Behandlung verloren haben, fest, dass „der Patient durchaus noch nicht geheilt ist" ${ }^{\prime 3}$.

Somit hat die Immunisierung des Menschen gegen Tuberkulose in ihren Enderfolgen keinen wesentlichen Fortschritt gemacht. Es mag dies sonderbar erscheinen, wenn wir bedenken, wie kolossal die Anstrengungen des menschlichen Geistes in dieser Richtung sind, und was für grosse wissenschaftliche Fortschritte die Bakteriologie zu verzeichnen hat. Andererseits lässt sich dieser Stillstand der Immunisation gegen Tuberkulose auf dem "toten Punkt" durch den gewichtigen Umstand rechtfertigen, dass die biologische Wirkung des Tuberkulins oder der. Tuberkuline auf den Organismus bis jetzt in

1) Ibidem.

) Beiträge zur experimentellen Therapie. Heft 5. S. XV.

3) III. Versammlung der Tuberkulose-Ärzte. Berlin. 1906. 
einen dichten Nebel gehüllt ist. Zwar sind uns die äusseren, klinischen Symptome der Tuberkulinreaktion genau bekannt, doch wissen wir nichts näheres über die Wirkung des Tuberkulins auf die Zellen des Organismus.

Aus der Geschichte des Tuberkulins ist bekannt, dass Koch nur die pathologisch-anatomischen Veränderungen infolge Tuberkulinwirkung erklären konnte, und dass diese Erklärung einseitig war, denn zugleich mit der Nekrose des tuberkulösen Gewebes kann eine Dissemmination des Prozesses aus den Herden in das gesunde Gewebe erfolgen, wie dies die Beobachtungen namhafter Pathologen zugleich mit den Untersuchungen Kochs dargetan haben. Geben wir zu, dass das Tuberkulin diese schädliche Wirkung nicht besitzt, sondern nur die positive Eigenschaft inne hat, im Sinne der Nekrose des kranken Gewebes und seiner Elimination aus dem Organismus zu wirken, so beschränkt sich doch darauf allein die biologische Wirkung des Mittels auf den ganzen Organismus nicht. Daher stammen die fortwährenden Versuche, diese Wirkung näher zu erklären. Wie sehen nun die Erfolge dieser Versuche aus?

Wie bekannt, ist die Theorie von Hertwig, welcher versucht hat, die Wirkung des Tuberkulins auf den tuberkulösen Organismus durch eine negative "Chemotaxis" der Leukozyten gegeniiber dem verdünnten, von aussen gebrachten Tuberkulin zu erklären - durch die Theorie von Wassermann widerlegt worden. Aber auch diese, anfangs enthusiastisch aufgenommene Theorie, wurde bald durch die Arbeiten von L. Rabinowitsch, Morgenroth, Weil, Besredka und anderen erschüttert. Einen sehr ernsten Stoss erlitt diese Theorie durch die Arbeiten von Wolff-Eisner und v. Pirquet, welche handgreiflich bewiesen haben, dass die Tuberkulinreaktion bei Tuberkulösen in gesunden Geweben - Haut und Bindehaut - erfolgt, also nicht, wie Wassermann behauptet, nur in der Lmgebung der tuberkulösen Herde, infolge Verbindung von injizirtem 'Tuberkulin mit dem Antituberkulin der Gewebe.

Somit kommen wir auf die Frage zurück, worauf das Wesen der Tuberkulinreaktion beruht? v. P irquet versucht es, dieselbe durch die "Allergie" zu erklären, in welche der Organismus unter der Wirkung eines ihm einverleibten fremden Eiweisses - also auch durch solches in Gestalt verschiedener bakteriologischer Präparate versetzt wird. Trotzdem jedoch diese Theorie auf positiven Daten aufgebaut ist, scheint es zweifelhaft, ob sie imstande sein wird, in verschiedene komplizierte $\mathrm{Phänomene}$ aus dem yon uns beriihrten $\mathrm{Ge}$ biete Licht zu bringen. 
Schon die Wirkung des fremden, nicht aus Bakterien stammenden Eiweisses bietet seltsame Erscheinungen. Nehmen wir z. B. die passive Übertragung der "Anaphylaxie" auf frische Tiere durch Einspritzung von Serum „anaphylactisierter" Tiere. Soviel uns aus der uns zugänglichen Literatur bekannt ist, besitzt diese Erscheinung kein Analogon in grösserem Masse bei der Anwendung bakteriologischer Tuberkulinpräparate an Tieren und Menschen.

Ähnliche Versuche misslangen z. B. vor zwei Jahren U. Frie demann, wie dies übrigens der Autor selbt zugibt; die Versuche wurden angestellt mit Serum, welches dem Blute ron mit Injektion von Mischkulturen TBC und Ptbc behandelten Meerschweinchen entstammte und den gesunden, nachträglich einer Tuberkulininjektion $(0.4 \mathrm{ccm})$ unterworfenen Meerschweinchen injiziert wurde. Es zeigte sich dabei kein Unterschied $z$ wischen den mit Serum vorbehandelten und den frischen Meerschweinchen (18). Dagegen muss bemerkt werden, dass analoge Versuche partiell Y $\mathrm{Ymanouchi}$ und Bauer gelungen sind, und zwar nicht nur mit "homologem", sondern auch mit "heterogenem" Serum. Ersterer injizierte Kaninchen das Blut tuberkulöser Menschen oder Leichen; - nach zweimaliger (innerhalb 24-28 Stunden erfolgter) Injektion eines T oder BF (.. Bouillon filtré Denys") oder verschiedener Tuberkulin.Präparate, oder Kochsalzextrakte aus tbc erhielt er deutliche Symptome von Anaphylaxie. Aber das Blut ron tuberkulösen Meerschweinchen oder Hunden, welche subkutan mit Tuberkelbazillen-Kulturen geimpft wurden, rief bei Ka n in ch en keine Symptome von Anaphylaxie hervor (77).

Die Versuche Bauers, welcher als anaphylactisierendes Serum das Serum tuberkulöser Meerschweinchen und Menschen verwandte, riefen bei Meerschweinchen deutliche Anaphylaxie hervor, vorausgesetzt, dass die Tuberkulinprobe nicht eher als 15 Stunden nach Injektion des Serums ausgeführt wurde; am deutlichsten waren die Symptome der Anaphylaxie, wenn das Tuberkulin 24-48 Stunden nach dem Serum eingespritzt wurde (4).

Dabei betont Verfasser die Tatsache, dass die Meerschweinchen, auf welche die Tuberkulinüberempfindlichkeit passiv übertragen wurde, gar nicht tuberkulös waren und es auch nicht wurden, was die 1-3 Monate nach den Versuchen dieser "passiven Anaphylaxie" ausgeführten Sektionen bewiesen (5).

Stellen wir die Ergebnisse der Versuche von Friedemann, Yamanouchi und Bauer zusammen, so sehen wir, dass hier vieles unklar und widersprechend ist. Auch in dem Verfahren der präventiven Behandlung der Anaphylaxie selbst, welches z. B. von Besredka (9) angegeben wurde, gibt es so merkwürdige Erscheinungen, 
dass dieselben eine festere theoretische Begründung rom biologischen Standpunkte erfordern. Trotz des unzweifelhaften Wertes des Experimentes bei der Anaphylaxie, beobachten wir also so paradoxe Phänomene, dass man dieselben bis jetzt auf biologischer Grundlage in einen harmonischen Zusammenhang noch nicht bringen kann. Es entsteht nun die Frage, ob man durch die v. Pirquetsche Theorie der Allergie verschiedene Fragen über die Wirkung von Tuberkulinpräparaten auf den menschlichen Organismus erk]ären kann. Warum fehlt z. B. die v. Pirquetsche oder W-Eisnersche Reaktion bei schwerkranken Tuberkulösen? Darauf wird mit einem Gemeinsatze geantwortet: weil ein solcher Organismus mit Tuberkulin-Toxinen überlastet ist. Aber Beweise dafür fehlen. Auf Grund seiner Versuche behauptet $W_{\text {olf }}$-Eisner, dass man bei Schwerkranken des öfteren kein Gewebstuberkulin findet, weil dasselbe entweder von den Phagozyten absorbiert, oder durch entsprechende Rezeptoren im Bindegewebe oder anderen Organen aufgefangen wurde. Jedenfalls verschwindet dasselbe aus dem Serum. Zweitens, falls nach der v. Pirquetschen Theorie "Antikörper" existieren, muss ein jedes Einführen von "Antigen" (in unserem Falle des Tuberkulins) in den Organismus sowohl bei Schwer- als auch bei Leichtkranken eine Reaktion hervorrufen; der Unterschied kann nur ein quantitativer, nicht qualitativer sein.

Weiter führen ernste Argumente gegen v. Pirquet, $\mathrm{Hamburger}$ (23) und W.E is ner. Und in der Tat, warum ruft wiederholtes Einführen von Tuberkulin in den gesunden Organismus keine Reaktion hervor, welche nach den Grundlagen der v. Pirquetschen Theorie zustande kommen soll? Gegen die "Allergie" führt Wolft$\mathrm{E}$ is $\mathrm{n}$ e $\mathrm{r}$ auch direkt entgegengesetzte Erscheinungen an, z. B. die durch Link nachgewiesene, bei gesunden Leuten bei erster Berührung mit dem Toxin des Typhus- oder Paratyphus- oder Kolibazillus auftretende lokale Reaktion. Diese Erscheinung wird zwar - im Gegensatz zu Tuberkulin - dadurch erklärt, dass dies primärgiftige Toxine seien, während das Tuberkulin zu denselben nicht gehört. Diese Erklärung könnte man provisorisch gelten lassen. Aber warum ist in diesem Falle, die bei erster Anwendung von entsprechend konzentriertem Diphtherietoxin bei gesunden Leuten auftretende lokale Reaktion schwächer, oder warum tritt sie, wie Schick nachgewiesen hat, bei Diphtheriekranken und $\mathrm{m}$ it $\mathrm{S}$ er u $\mathrm{m}$ behandelten Kindern nicht auf? Schick gibt zu "mit diesen Ergebnissen ist die Auffassung der Diphtheriekutanreaktion als reine allergische Reaktion unvereinbar" (58).

Somit wird durch die v. Pirquetsche Theorie eine ganze Reihe 
von Phänomenen aus dem Gebiete der Wirkung bakteriologischer Präparate im allgemeinen nicht erklärt; weiter betrifft dies die uns unmittelbar interessierende Frage, närnlich die Wirkung des Tuberkulins auf den Organismus. In bezug auf diese Theorie macht $M$ ï $l 1 \mathrm{er}$ die richtige Bemerkung, ,dass die gesteigerte allergische Reaktionsfähigkeit", die es dem immunisierten Organismus ermöglicht die Einführung kleinster Antigenmengen mit ungewöhnlich rascher und intensiver Produktion von Antikörpern zu beantworten, einen bedeutenden Vorteil für ihn bedeuten muss, "andererseits aber haben dagegen die mannigfaltigen Phänomene der Anaphylaxie, wenigstens soweit wir bis jetzt beurteilen können, eher den gegenteiligen Effekt und scheinen auf den ersten Blick eher dazu angetan, die Wiederstandsfähigkeit des Organismus herabzusetzen, als sie zu erhöhen" (39, Seite 305̃).

Indem Wolff-Eisner die Theorie v. Pirquets einer Kritik unterwirft, stellt er seine eigene auf; dieselbe hat mit der letzteren gemeinsam, dass jedes fremde Eiweiss, also auch das bakterielle als Gift für den Organismus betrachtet wird. Der Unterschied zwischen der Giftigkeit verschiedener Eiweissarten ist nur ein quantitativer. Jedes fremde Eiweiss wirkt, wie Endotoxin (74).

Bei dieser Theorie wollen wir uns einen Augenblick aufhalten und uns die Frage vorlegen, ob sie uns die komplizierten Erscheinungen aus dem Gebiete der spezifischen Therapie der Tuberkulose erklärt. Nach Wolff-Eisner lassen sich diese Erscheinungen durch „Lysine" erklären, welche aus dem Leib des Bacillus Endotoxine auslösen; das Freimachen dieser Endotoxine, im Verein mit der Bildung der Antitoxine und ihrer Rolle bei der Immunisierung des Organismus, hat Wolff-Eisner bereits vor fünf Jahren umfassend und sehr klar dargestellt (70). Daneben tritt in den Vordergrund das individuelle Moment, welches an und für sich, speziell dem Tuberkulin gegenüher eine "teleologische Erscheinung", d. h. die Überempfindlichkeit ist. Nach Wolff-Eisner spielt sie bei den Krankheiten mit bakteriolytischer Form der Immunität „eine grosse, ja eine entscheidende Rolle am Ausgang der Infelstion" (76, S. 309).

Wolff-Eisner sagt. das Tuberkulin verdankt seine Wirkung weder den säurefesten Substanzen, noch den albumosen; die Wirkung ist aber an die Splittcr der Tuberkelbazillenleiber geknuipft (73).

Diese Wirkung beginnt mit einer "Lysis" der in dem Tuberkulin enthaltenen Bazillensplitter, welche von Daels entdeckt, später an Präparaten von W.-Eis ner demonstriert wurden. Diese Splitter sind nach dem Passieren des Berkefeldschen Filters nur ultramikroskopisch nachzuweisen. In diesem Falle wird ihre Wirkung nur 
quantitativ verschieden sein. Immerhin bleibt der "Splitter" das einzige aktive Element des Tuberkulins (73 u. 75).

Dass die Rolle der Endotoxine und Lysine im Verlaufe der Infektion bedeutend ist, ist bekannt, doch sind die Grenzen ihrer Wirkung noch ungenügend gezogen; es bleibt noch die Frage ungelöst, ob dieselben richtzuweilen ein doppelschneidiges Schwert, je nach den verschiedenen Stadien der Infektion, bilden.

Ebenso wichtig für den Kampf des Organismus mit der Infektion ist die Rolle der Überempfindlichkeit; (nach Wolff-Eisner sogar wichtiger, als die der "Lysine“). Leider ist die Rolle dieses so speziell individuellen Symptomes rätselhaft. Schon sein Erfinder, Behring, nannte es "paradoxal", und es wurde darüber schon viel geschrieben; speziell die Arbeit von Löwenstein und Rappoport ist in Bezug auf Tuberkulose bekannt. Noch stehen wir auf demselben Punkte, wonach die Überempfindlichkeit eine Phase der Immunität darstellt, nur weiss man nicht, welche Grenze zwischen dem einen und dem anderen Symptome liegt. Die Praxis belehrt uns, dass bei der spezifischen Behandlung der Tuberkulose gerade die Bestimmung dieser Grenze von ungemeiner Bedeutung ist. Die umfangreichen Ausführungen $\mathrm{W}$ olf $\mathrm{f}-\mathrm{E}$ is n ers erklären diese Frage unseres Erachtens ungenïgend, und seine, wie auch die v. Pirquetsche Theorie lassen die verschiedenen Fragen der spezifischen Behandlung der Tuberkulose überhaupt unaufgeklärt. Wolff-Eisner behauptet ofters, dass nur derjenige auf Tuberkulin reagiere, welcher eben erst mit tbc infiziert wurde oder es jemals war, denn nur in solchem Falle enthalte der Organismus .Lysine", die eine Conditio sine qua non für die Befreiung der Endotoxine von den ..Splittern", also für die Tuberkulinwirkung seien. Nach WollfE is ner besitzen gesunde Leute keine ..Lysine“, reagieren somit nicht auf Tuberkulin. Doch kommt es vor, dass anch gesunde Leute reagieren. Bei der Erklärung dieses Widerspruchs gerät Wolff-E is ner mit sich selbst in Widerspruch. indem er annimmt, dass ,auch der gesunde Körper, der mit Tuberkelbazillen noch niemals in "Reaktionskontakt getreten ist, einige Lysine enthält" (76, S. 261). Umgekehrt erklärt er den Mangel einer Reaktion beim gesunden Menschen nach wiederholten Tuberkulininjektionen - - die die Bildung ron Lysinen und die Entstehung der Überempfindlichkeit herbeiführen sollten in der Weise, "dass nur lebende Tuberkelbazillen die Bildung dieser Lysine herbeizuführen scheinen" (Ibid S. 265),

Hier liegt abermals ein Widerspruch vor, denn Verf. behauptet mehrmals prinzipiell, dass der Unterschied in der Wirkung lebendiger und toter Tuberkelbazillen auf dèn Organismus nur ein quanti- 
tativer sei. Zwecks Erklärung dieses deutlich qualitativen linterschiedes in der Wirkung des Tuberkulins und lebendiger Tuberkelbazillen behauptet er, dass weitere Untersuchungen darüber Aufk]ärung geben werden, „ob es sich um quantitative Verhältnisse handelt, oder ob etwa dem lebenden Tuberkelbazillus besondere Eigenschaften zukommen, die seinen Derivaten abgehen" (Ibid. S. 265).

Die Widersprüche in bezug auf verschiedene Einzelheiten der spezifischen Therapie treten noch deutlicher auf, wenn man sich die Unklarheiten vergegenwärtigt, welche über den beiden Ausgangspunkten der Wolff-Eisnerschen Theorie schweben, nämlich den "Lysinen" und der Überempfindlichkeit. Einmal scheint es, als ob sie nach ihm bei der Immunisierung gegen Tuberkulose eine überwiegende Rolle spielen werden, obwohl er ein anderes Mal behauptet, dass sie ,allein nicht in der Lage sind den Kampf gegen die 'Tuberkulose erfolgreich zu entscheiden" (Ibid. S. 293). - Nach diesem also scheint die Überempfindlichkeit die Hauptrolle zu spielen, aber Verf. gibt selbst zu, dass wir es bei der Verwendung des Tuberkulins „bisher nicht immer in der Hand haben, die Überempfindlichkeitserscheinungen so zu beherrschen, dass sie mit Nutzen therapeutisch verwendet werden können" (Ibid. S. 294).

Mit diesen Schwankungen hängt die uns Klinikern am nächsten interessierende unklare Frage der Indikationen für die 'Tuberkulinbehandlung zusammen. Bei Wolf $\mathrm{f}-\mathrm{E}$ is $\mathrm{n}$ er finden wir nur zwei deutliche Indikationen: Hautlupus oder lokalisierte Knochentuberkulose einerseits, weit vorgeschittene Kranke andererseits. Im ersten Fall soll das injizierte Tuberkulin eine Umstimmung des ganzen Organismus hervorrufen, weil „aus so lokalisiertem Herde keine Stoffwechselprodukte (Tuberkulin) in den Kreislauf gelangen", im zweiten soll die Tuberkulinwirkung „durch Bindung an Rezeptoren in minder lebenswichtigen Organen die durch Tuberkulinresorption aus dem Herde gesetzten Schädigungen (Fieber, Nachtschweisse etc.) vermindern oder aurheben" (Ibid. S. 295 u. 296).

Diese Behauptungen lassen sich möglicherweise an einem grossen klinischen Material bestätigen, aber sie besitzen, bis jetzt wenigstens, eher den Charakter einer Hypothese. Überhaupt während die Theorie von Wolff-Eisner uns den Mechanismus der biologischen Wirkung des Tuberkulins darlegt, bringt sie leider ebenso wie die übrigen Theorien, nicht genügend Licht in verschiedene klinische Phänomene der spezifischen Therapie der Tuberkulose.

Stellen wir diese verschiedenen Theorien zusammen, so kommen wir wieder auf die prinzipielle Frage zurück, welche sich uns aufdrängt, wenn wir die beiden Haupttheorien von der Immunität des Organismus 
gegenüber der Infektion betrachten. Denn wissen wir schliesslich nicht, ob die spezifische Therapie der T'uberkulose zu einer Steigerung der Phagozytose und einer Eliminierung des Bazillus auf diesem Wege führt, oder ob dies durch Antikörperbildung vom Charakter der Bakteriolysine, oder endlich durch Antitoxinbildung geschieht, oder aber durch beides zugleich? Wir wollen noch hinzufügen, dass die Rolle der Opsonine auch noch nicht genügend aufgeklärt ist.

Wäre die Tuberkulose hauptsächlich eine toxische-Krankbeit, wie man dies auf Grund der ersten epochemachenden Arbeiten Kochs und seiner Tendenz zur "Giftimmunisation", und noch heute in betracht der ïblichen Terminologie "Intoxikation des Organismus mit Tuberkulingiften" annehmen könnte, so könnte man sich die Heilung durch die Wirkung entsprechender Antitoxine auf dem Wege passiver, oder aktiver Immunisierung rorstellen. Wir wissen, dass die Versuche der ersten Richtung trotz Maraglianos Behauptungen keine erfolgreichen Resultate brachten. Auf dem Wege der aktiven Immunisation ist wiederum experimentell die Bildung von Ektoantitoxinen angesichts unserer mangelnden Kenntnis von Ektotoxinen bei Tuberkelbarillen bis jetzt nicht festgestellt worden. Aus der Literatur ist bekannt, dass die Theorie der Antitoxinbildung infolge Tuberkulinbehandlung von Sahli aufgestellt wurde; indessen ist sie nicht auf experimentellem, sondern auf rein spekulativem Wege entstanden.

Was nun die anderen, nicht näher definierten Antikörper anbelangt, muss zunächst bemerkt werden, dass Pickert und Löwenstein im Blutserum Tuberkulöser "Tuberkulinantikörper" nachgewiesen haben, welche die Eigenschaft besitzen "die spezifische Wirkung des Tuberkulins auf die Haut Tuberkulöser aufuheben bezw. abzuschwächen" (43). Ferner haben sie gezeigt, dass diese Antikörper nicht nur bei spezifisch behandelten Kranken auftreten, sondern auch bei jenen, welche mit der gewöhnlich hygienisch-diätetischen Methode behandelt werden, und deren Organismus eine spezielle Widerstandsfähigkeit gegen die Tuberkelbazilleninfektion besitzt; somit besteht nach den Autoren ein gewisser liausaler Zusammenhang zwischen "Antikörpern" und der Immunisierung des Organismus. Es ist das eine wichtige neue Tatsache, bei deren Beurteilung jedoch grosse Vorsicht geboten ist, wozu uns vorurteilsfreie Betrachtung der Immunisationsfrage berechtigt.

In Zusammenhang damit seien hier die Experimente von $\mathrm{Ch}$ ristian und Frl. Rosenthal erwähnt, welche bei Meerschweinchen nach Injektion von $\mathrm{BE}$ „Antikörper" nachgewiesen haben, aber selbst betonten, dass „sich über deren Natur indes noch nichts aussagen lässt" (12). 
Engel und $\mathrm{Bau}$ er haben auch durch die Methode der Komplementablenkung im Blutserum tuberkulöser Kinder und Erwachsener komplementbindende Antikörper gefunden. Bei Kranken, deren Allgemeinzustand ein zufriedenstellender war, waren diese Körper in grosser Menge vorhanden. Diese Autoren vermuten, dass diese Antikörper "den toxischen Bestandteil des Tuberkebazillus binden und ihn so nach Art der Antitoxine von den Herden des Organismus ableiten" (17). Doch fehlt es für diese Vermutung an sicheren Beweisen. -

Die Frage der Antikörperbildung bei Tuberkulose wartet hartnäckig auf Entscheidung auf dem Wege des Experimentes, umsomehr, als infolge des von $\mathrm{W}$ assermann bei Tuberkulösen nachgewiesenen "Antituberkulins" in den Gemütern grosse Verwirrung herrscht. Bekanntlich haben nach Wassermann, J. Cohn, Lüdke, WolffE isner, P. Bermbach u. a. sowohl bei tuberkulösen Tieren, denen man Tuberkulin oder tote Tuberkelbazillen eingespritzt hatte, als auch bei spezifisch und nichtspezifisch behandelten Menschen im Blute "Antituberkulin" nachgewiesen. Wir wollen auf die Einzelheiten dieser Autoren nicht eingehen. Es handelt sich für uns nur um die Ergebnisse. Mit Ausnabme von Bermbach, welcher diesen Körper "Tuberkuloseimmunkörper" nennt (7), ohne seine Rolle bei der Immunisierung gegen Tuberkulose näher zu bestimmen -- betonen die übrigen Autoren, dass das „Antituberkulin" für den Organismus kein Antitoxin bedeutet, dass es nur die Rolle eines komplementbindenden Körpers spielt, dessen eigentliches Wesen uns unbekannt ist, und dass schliesslich wegen der Verwirrung der Begriffe, der Name "Antituberkulin" gestrichen und durch einen gleichgültigen Terminus ersetzt werden sollte.

In der Tat, als S. Cohn das Tuberkulin mit dem „Antituberkulin" in entsprechendem Verhältnis (bei welchem die Bindung des "Komplements" erfolgt) mischte und den Kranken injizierte, bekam er eine ähnliche Reaktion, wie bei $1 \%$ Tuberkulin; bei gesunden Leuten fehlte die Reaktion. Im Einklang mit diesen Versuchen betont er die klinische Beobachtung, dass, ungeachtet des hohen Gehalts des Blutes an "Antitnberkulin", die Krankheit rasch vorwärtsschreiten kann und umgekehrt (13).

Berücksichtigen wir eine ganze Reihe von Widersprüchen, welche die Wirkung der Tuberkelbazillen-Präparate auf den menschlichen, tuberkulosekranken Organismus bietet, so kommen wir zu den vorurteilsfreien Schluss, dass die Frage der Immunisierung gegen Tuberkulose mit Hilfe dieser Präparate, also die spezifische Behandlung 
dieser Krankheit rom theoretisch-wissenschaftlichem Standpunkte noch nicht als gelöst betrachtet werden kann.

Bedenken wir jedoch, dass der Empirismus seit Jahrhunderten eine so bedeutende Rolle in der Medizin gespielt hat und noch heute einen ansehnlichen Platz einnimmt, so muss man sich fragen, ob nicht die spezifiische Behandlung der Tuberkulose auf diesem Wege eine feste faktische Begründung finden wird. Diese Frage erscheint uns um so zeitgemässer, als die unbedingten Anhänger der spezifischen Behandlung der menschlichen Tuberkulose, als Beweis, dass die Frage schon heute entschieden ist, zwei wichtige Argumente anführen: die Tierexperimente und die Statitstik.

Es ist unmöglich die ganze grosse Zahl von Tierversuchen anzuführen, um so mehr als die Autoren keine Statistik von Dauererfolgen angeben. Wir wollen uns ganz kurz bei den wichtigsten, vor allem bei den Versuchen v. Behrings aufhalten.

Bereits in unserer frïheren Arbeit, als wir uns auf die Experimente von Moussu und die von ihm zitierten Versuche anderer Tierärzte beriefen, haben wir bemerkt; dass die intravenöse Impfung menschlicher Kulturen nach der B eh r in g schen Methode keine dauernden Erfolge gibt, dass das Rind nur für eine gewisse Zeit - für ein Jahr - immunisiert wird, später aber einer natürlichen Infektion unterliegt und an allgemeiner Tuberkulose zu Grunde geht; die Ansicht von Moussu wird durch $\mathrm{Eber}$ gestützt. $\mathrm{Zu}$ analogen Schlüssen gelangt auch Prof. Nowak auf Grund von 332 im Zeitraume zwischen 1903-1908 in Galizien ausgeführten Impfungen. Derselbe behauptet, dass „man zwar mittels der Behringschen Methode dem Tiere eine bedeutende. Widerstandskraft gegen künstliche Infektion mit giftigen Perlsuchtsbazillen beibringen, dass aber die Methode jedes praktischen Wertes entbehrt, denn sie ist nicht im Stande, die so immunisierten Kälber vor natürlicher Infektion mit Tukerkulose zu schützen" (40).

Fernerhin soll diese Methode nach Klimmer für das Vieh gefährlich sein, weil der Tuberkelbazillus in die Milch übergehe. Dagegen führt Klimmer seine eigene Methode an, welche auf Verwendung avirulenter Tuberkeibazillen beruht. Auf die Einzelheiten werden wir an dieser Stelle nicht eingehen, wir wollen nur bemerken, dass die Methode nach dem Verfasser völlig gefahrlos ist und sowohl vor einem weiteren Fortschreiten der Tuberkulose - was durch Sektionen bewiesen wird - als auch vor künstlicher Infektion mit virulenten PTBC schützen soll (28). Es fragt sich nur, ob diese Immunisierung erfolgreich und dauernd sein wird, wenn die Infektion auf nat ürlichem Wege erfolgt. Eine solche lrage ent- 
steht auch bezüglich der Methode v. Heymanns (Einführen von Collodium-Säckchen mit tbc-Kulturen unter die Haut oder in die Bauchhöhle vom Rinde); nach dem Verfasser vermag man hierdurch das Tier sicherer als durch intravenöse Injektionen zu immunisieren. In solchem Falle würden hier Ectotoxine des tbc das wirksame Element sein, wenn allerdings infolge Mazeration der tbc durch die Wand des Säckchens nicht Endotoxine durchtreten. Eber unterzieht die Erfolge der in Belgien v. Heymanns angewendeten Methode einer Kritik und bezweifelt stark, ob dieselbe bezüglich ihrer Dauer die in Deutschland üblichen Methoden übertrifft (16). Soviel uns aus der zugänglichen Literatur bekannt ist, verdienen die in letzter Zeit mit grosser Exaktheit an Laboratoriumstieren von Römer und von Hamburger ausgeführten Versuche eine spezielle Beachtung. Das Eingehen auf die Einzelheiten würde den engen Rahmen unserer Arbeit übersteigen, wir wollen nur den Endergebnissen einige Worte widmen, um so mehr, als Römer in gewissen Erscheinungen bei Tieren nach einer Analogie mit entsprechenden Phänomenen der Evolution der Tuberkulose beim Menschen forscht.

Die Ergebnisse sind kurz folgende: Die Infektion der Meerschweinchen mit lebendigen, aber in ihrer Virulenz geschwächten tbc-Kulturen in von $R o ̈ m e r$ genau festgestellten Dosen (wir unterzeichen das Wort lebendige, denn tote und avirulente Kulturen wirken nach dem Verfasser nicht immunisierend) ${ }^{1}$ ) ruft eine solche Immunität gegen nachfolgende Masseninfektion mit virulenten PTBCKulturen oder mit Schweinebazillen hervor, dass 1. die so behandeiten Meerschweinchen einige Mal länger leben als die Kontrolltiere, denen man vorher keine tbc-Kulturen eingeimpft hatte, 2. dass sie nicht, wie die Kontrolltiere, an akuter disseminierter Tuberkulose zugrunde gehen, sondern sie „erweisen sich gegenüber einer ziemlich intensiven zweiten Infektion nahezu völlig immun, da diese nur zu einem lokalisierten und Heilungstendenz zeigenden Tuberkuloseherd Veranlassung gab“ (54, Seite 7). Doch behauptet zugleich Verfasser, dass bei dieser "völligen Immunität" sich aber "unter dem Reize der Zweitinfektion die Neigung zur Kavernenbildung in den Lungen einstellte, in denen ohne diese Zweitinfektion anscheinend nur eine chronische indurative tuberkulöse Pneumonie ohne Neigung zur Erweichung und Höhlenbildung sich gebildet hätte." (Ibid. Seite 12.)

Die Ergebnisse sind somit nicht ganz überzeugend. Aber, was

1) Wir erinnern daran, dass Klimmer, welcher behauptet, die sichersten Erfolge zu haben, zur Immunisierung des Rindes eben avirulente Tuberkelbazillenkulturen gebraucht. 
wichtigter ist, der Verfasser hat die Beobachitung gemacht, dass sich die mit natürlicher, cbronischer Tuberkulose behafteten Meerschweinchen der Masseninfektion gegenüber wie die vorbehandelten verhalten.

Daraus werden per analogiam weitgehende Schlüsse gezogen, dass ein Mensch, welcher einmal einen wenig ausgedehnten tuberkulösen Prozess durchgemacht hat, gegen sekundäre Infektion autoimmunisiert sein kann. Es fragt sich nur, ob dies eine Reinfektion von aussen oder eine metastasierende "Autoinfektion" ist. Verfasser ist im Sinne v. Behrings Anhänger der letzteren. Sehen wir von der ungelösten Frage ab, welche von den beiden weiteren Infektionen im Verlaufe der Tuberkulose eine dominierende Rolle spielt, so müssen wir bemerken, dass schon früher (u. a. Maragliano und Marfan) klinische Beobachtungen gemacht wurden, nach welchen ein Mensch, welcher eine leichte Tuberkulose glücklich überstanden hatte, gegen weitere Infektion autoimmunisiert werden kann. IDiesen Beobachtungen kann man aber direkt entgegengesetzte und zwar sicher zahlreichere gegenüberstellen. Und deshalb sollten vergleichende Schlüsse aus Tierversuchen, unseres Erachtens, in diesem Falle sehr vorsichtig gezogen werden. Obwohl die Versuche $R$ ö mers sehr wertvoll sind, so kann man im grossen und ganzen aus ihnen nur den einen sicheren Schluss ziehen, dass die auf bestimmte Art mit tbc-Kulturen behandelten Versuchstiere zu einer hochgradigen Immunität gegen künstliche Infektion mit $\mathrm{P}$ tbc virulenten Kulturen gelangen können, aber zu ähnlichen Schlüssen kommen selbst die Kritiker der "Bovorakzination" Behrings. Es handelt sich aber hier um etwas Weitergehendes, d. h. um eine Immunisation gegen nat ürliche Infektion. Eine solche Immunität erzielten beim Rinde weder Mous su, noch $\mathrm{Eber}$, noch $\mathrm{Nowak}$ oder andere Forscher, welche die Behringsche Methode versuchten. In den Arbeiten Römers finden wir aber keine Versuche Tiere gegen natürliche Infektion $\mathrm{zu}$ immunisieren.

Die Versuche $\mathrm{Ha}$ mburgers, welche sich von den $\mathrm{R} \ddot{\text { ömerschen }}$ nur durch Verwendung ausser von tbc- auch von Ptbc-Kulturen zu Impfungen unterscheiden, lassen den Verfasser mit Recht vorsichtiger schliessen, dass man durch solche Impfungen ein Meerschweinchen gegen nachfolgende künstliche Infektion relativ immunisieren kann (21).

Stellen wir alle uns bekannten Ergebnisse der Immunisierung von Tieren zusammen, so lassen sich daraus keine Schlüsse ziehen, welche uns eine feste Basis für die spezifische Behandlung der menschlichen Tuberkulose liefern könnten. Denn eine dauernde Immunität von Tieren gegen natürliche tuberkulöse Infektion - ganz abgesehen 

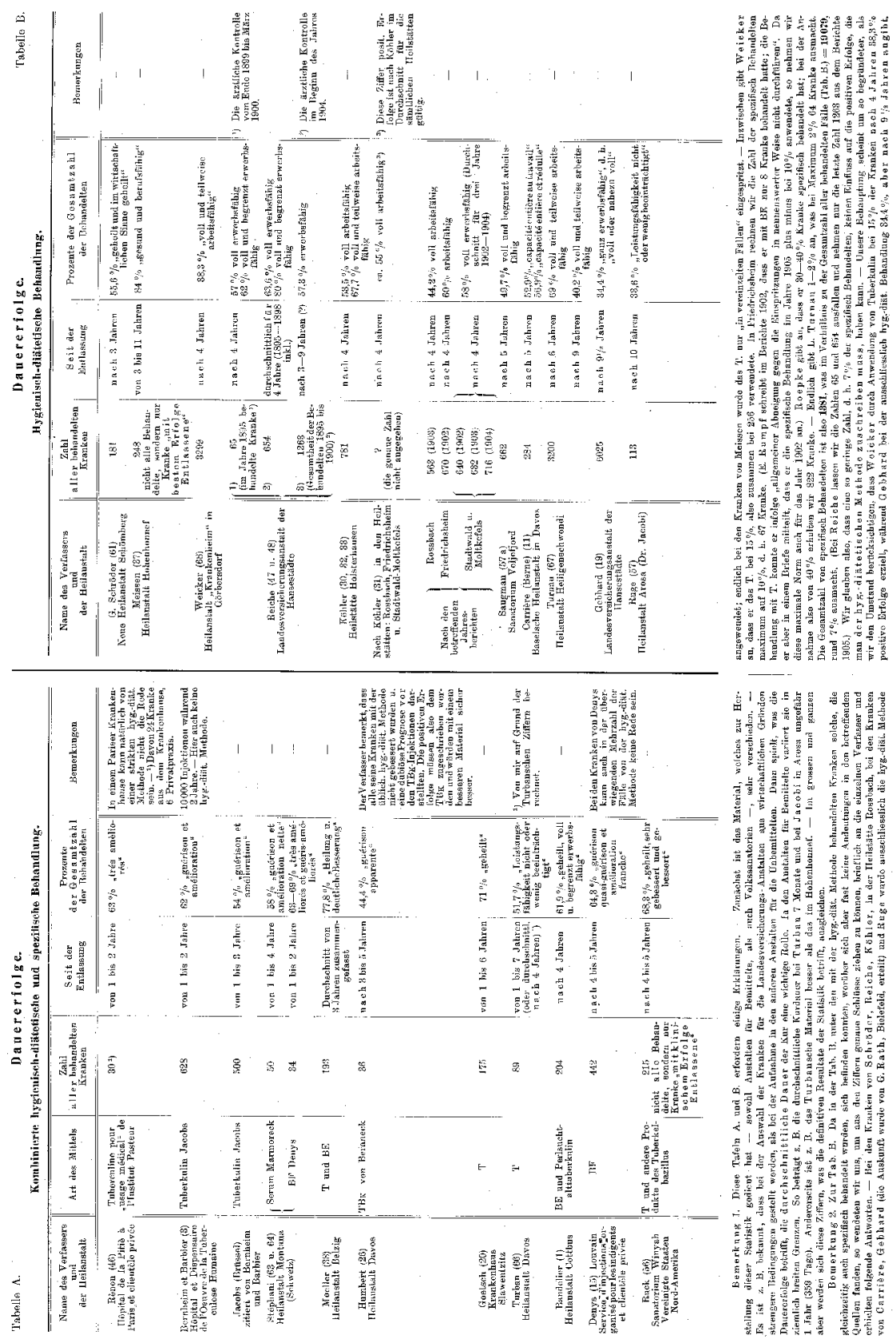
von dem Impfmateriale und den Impfmethoden - ist bis jetzt noch nicht bewiesen worden.

Sehen wir nun, wie es mit dem zweiten Argument der absoluten Anhänger der spezifischen Tuberkulosetherapie steht, welches von ihnen als Beweis des Wertes und der Superiorität dieser Methode gegenüber der gewöhnlichen hygienisch-diätetischen angeführt wird. Dieses zweite Argument ist die Statistik.

Das Operieren mit vergleichender Statistik bietet hier gewisse Schwierigkeiten und Ungenauigkeiten. Das bezüglich der hygienischdiätetischen Behandlung in verschiedenen Ländern, speziell in Hinsicht auf Entlassungserfolge, gesammelte Material ist sehr reichlich, besonders dasjenige des Kaiserlichen Gesundheitsamtes, während die die spezifische Therapie betreffenden Zahlen relativ dürftig sind. Was die Dauererfolge betrifft, so sind die Zahlen in den einzelnen Berichten sehr verschiedenartig und das in therapeutischen Versuchen verwendete Material auch sehr ungleichmässig. Zur Illustrierung dieser Verhältnisse fügen wir folgende Tafel bei.

Wenn wir diese Tafel ganz objektiv betrachten, können wir daraus keinen anderen Schluss ziehen als den, dass im Lichte der Ziffern der kombinierten-spezifischen Behandlung keine Superiorität über die übliche hygienisch-diätetische zukommt. Ein solcher Schluss wird noch fester begründet, wenn wir die Dauererfolge für eine und dieselbe Zeitperiode vergleichen: z. B. bei Bandelier $62 \%$ und bei $\mathrm{K}$ öhler $67 \%$ (beide nach vier Jahren). - Die Berechtigung unseres Schlusses wird aber noch schärfer hervortreten beim Vergleichen der Resultate, z. B. Rucks: $68,3 \%$ nach $4-5 \mathrm{Jahren}-$ mit Berücksichtigung, dass seine Dauererfolge die Kranken „mit klinischem Erfolge" betreffen - mit den Resultaten von Turnau: 69\% nach 6 Jahren, die "alle Patienten", also ohne Auswahl des Materials, betreffen.

Wenn wir von den Dauererfolgen zu den Entlassungserfolgen übergehen, so ergibt sich zwischen den beiden Methoden kein oder jedenfalls nur ein minimaler Unterschied:

B andelier (l. c.) z. B. gibt für 383 Lranke (BE und Perlsucht-Tuberkulin) $95,50 \%$ positive Erfolge ${ }^{1}$ )

$65,5 \%$ geheilt und voll erwerbsfähig, begrenzt erwerbsfähig.

1) Unsere Arbeit wurde schon zum Druck abgegeben als wir die umfassende Arbeit $B$ andeliers „Die Leistungsfähigkeit der kombinierten Anstalts- und 
Sch nöller (65) gibt für 211 Kranke (BF)
$88,2 \%$ positive Erfolge $\begin{cases}23.2 \% & \begin{array}{l}\text { wahrscheinliche } \\ \text { Heilung, }\end{array} \\ 49,8 \% & \text { bedeut.Besserung, } \\ 15,2 \% & \text { Besserung. }\end{cases}$

Ruck (l. c.) gibt für 1893 Kranke (T und verschiedene Tuberkelbazillenpräparate) $85,7 \%$ positive Frfolge

$47,8 \%$ anschein. geheilt, $37,9 \%$ gebessert.

$\mathrm{Ha}$ mel (27) dagegen gibt für ein kolossales $76,9 \%$ vollst ändige 15800 Kranke (mit hyg.-diät. Methode) behandelt) umfassendes Material Arbeitsfähigkeit, positive Erfolge in $90,3 \%$ partielle Arbeitsfähigkeit.

Fassen wir all das Gesagte in wenigen Worten zusammen, so sehen wir, dass in Anbetracht der verschiedenen, sich widersprechenden und wechselnden Theorien, der divergierenden Ergebnisse bei Tierexperimenten und der verschiedenen klinischen Methoden - die Frage der spezifischen Therapie der menschlichen Tuberkulose noch nicht abgeschlossen ist. Diese Zweifel treten noch dentlicher auf, wenn man den allgemeinen Charakter der Tuberkulose vom Standpunkte der herrschenden Theorien der Infektion und Intoxikation betrachtet. Es wurde schon oben die Frage gestreift, ob die Tuberkulose eine vorwiegend infektiöse oder toxische Krankheit ist. - Wie oben erwähnt, ist die Bildung von Anti-Ectotoxinen bei Tbc nicht bewiesen, obwohl die Versuche von Heymans und Haentjens bei Tieren und die Verwendung der „Filtrase" des letzteren beim Menschen dafür zu sprechen scheinen, dass die Ectotoxine bei der Immuni. sierung eine gewisse Rolle spielen. Es fragt sich aber, ob solche Ectotoxine nicht tatsächlich von ultramikroskopischen Partikeln freigemachtes Endotoxin im Sinne der Wolff-Eisnerschen Theorie ist. Indessen ist eine nähere Definition des Charakters der Tuberkulose, abgesehen von ihrer wissenschaftlichen Bedeutung - vom

Tuberkulinbehandlung bei der Lungentuberkulose* (Beitr. Bd. XV. Heft 1) die, wie der Verfasser es selbst behauptet das Ziel hat „durch die Grösse des Materials zu überzeugen" (Seite 43), erhielten. - Gewiss, das Material von 500 Kranken ist gross, die erhaltenen positiven Erfolge $\left(96,4 \%\right.$ ) sind glänzend und um $1^{\circ}:$ höher als bei den oben von $\mathrm{ihm}$ angegebenen 383 Kranken. - Wir erlauben uns jedoch zu zweifeln, ob die Resultate der spezifischen Behandlung selbst in den Händen des Verfassers, der hygienisch-diätetischen Behandlung allein in unvergleichlichem Masse überlegen sind“ (S. 4) - wie er es so entschieden behauptet - wenn wir berücksichtigen, dass $\mathrm{Hamel}$ für $15800 \mathrm{mit}$ der hygienischdiätetischen Methode behandelte Kranke $90,3^{\circ} \%$ positive Erfolge, also nur um $6 \%$ weniger, als Bandelier angibt. - Aus diesen Zahlen lassen sich die Schlüsse leicht ziehen. - 
klinischen Standpunkte aus, schon aus dem Grunde sehr erwünscht, weil sie zur Vereinfachung und Systematisierung der Heilmethoden führen würde.

Nach dem oben Gesagten würde sich auch die Aussicht auf eine passive Immunität bei der Tuberkulose als keine vielversprechende darstellen. - Wir bemerken, dass nichtsdestoweniger in den ersten Kliniken neben aktiver auch die passive Immunisierung verwendet wird, zwar in weit geringerem Masse, aber angeblich mit guten Resultaten.

Jedoch auch das Wesen der aktiven Immunität, die Bildung von verschiedenen "Antikörpern" ist - wie wir gesehen haben - bei weitem nicht genügend aufgeklärt und experimentell wenig bewiesen.

Unter dem Einflusse der Theorie Wolff-Eisners gewinnt der Gedanke mehr an Wahrscheinlichkeit, dass die Tuberkulose vor allem eine Infektionskrankheit ist, und zwar in dem Sinne, dass die aus dem Bazillus gebildeten Toxine - Endotoxine sind. Auf Grund seiner Arbeiten behauptet $\mathrm{L} \ddot{\mathrm{u}} \mathrm{dke}$, dass der tuberkulöse Organismus viel mehr mit Bazillen durchseucht ist, als bis jetzt im Sinne der Theorie der Toxinämie rermutet wurde, und dass die kranken Gewebe des Organismus und die ihnen am nächsten stehenden durch Tbc-Endotoxine und durch Resorption der von ihnen gebildeten Zerfallsprodukte vergiftet werden (36).

Diese Theorie bildet gewissermassen eine Ergänzung der WolffE is nerschen. Die Vereinigung beider kann uns verschiedene Symptome der Tuberkulose wie z. B. Fieber, Schweisse, Pulsfrequenz usw., sowie ihre Intensität durch quantitative Wirkung der Endotoxine erklären (72), aber vermag nicht den Mechanismus der Immunisation bei spezifischer, oder diätetischer Therapie zu erklären.

Wenn es richtig ist, dass die Tuberkulose hauptsächlich oder vielleicht ausschliesslich eine Infektionskrankheit ist und dank der Wirkung von Endotoxinen, welche aus dem Bazillus oder dem "Splitter" frei werden, "toxisch" wird, so entsteht weiter die Frage: was geschieht mit diesen Endotoxinen? Auf welche Weise werden dieselben extrazellulär durch die lebenden Säfte des Organismus neutralisiert? Ferner, welche Organe spielen hier die Hauptrolle? Wir wissen, dass die blutbildenden Organe, wie die Milz und das Knochenmark zugleich Sitz der Bildung von Antikörpern sind. Es wäre interessant, nachzuweisen, in welchen Organen oder Geweben die mit Endotoxinen gesättigten Zerfallsprodukte tuberkulöser Gewebe zugrunde gehen ${ }^{1}$ ).

1) Es ergibt sich aus der jüngsten Arbeit von Schröder, dass die Milz Schutzkörpe: gegen menschliche Tuberkelbazillen enthält (60); aus den Arbeiten anderer Autoren ist die schützende Tätigkeit der Lymphdrüsen bekannt. 
In Zusammenhang damit und mit der Tatsache, dass die Theorie der "Allergie" und der "Lysine" uns nur ungenügend die verschiedenen Erscheinungen des Kampfes vom Organismus mit Bazillen erklären, entsteht die Frage, ob weitere Forschungen anderen Antikörpern nicht eine wichtigere Rolle zuerkennen werden?

Nach den Forschungen von Böhme z. B. fehlen die Bakteriotropine im Blutserum gesunder Leute, dagegen treten sie häufig bei schwerkranken Tuberkulösen und in grosser Menge bei allen mit BE behandelten Kranken auf (10).

Aus all dem ergibt sich der Allgemeinschluss, dass solange die Ergebnisse so grosser menschlicher Geistestätigkeit noch zu keinen strengen Gesetzen formuliert werden können, welche uns den harmonischen Zusammenhang verschiedener biologischer Phänomene zu erklären vermögen, bei der spezifischen Therapie der Tuberkulose mit Vorsicht verfahren soll. - Für den Kliniker aber ergibt sich aus dem Gesagten die praktische Frage: Wie soll man sich der spezifischen Therapie gegenüber verhalten? Lehnt man sie ab so hiesse dies die Errungenschaften der Wissenschaft, wie auch die Tatsache, dass die spezifische Behandlung in letzten Jahren immer mehr angewendet wird, ignorieren. - Nach Bandelier und R o epke hat sich die Zahl der deutschen Heilstätten, die das Tuberkulin anwenden, von 1905 bis 1908 mehr als verdoppelt (2).

Nimmt man sie blind an, so wäre dies ein Identifizieren von festen Tatsachen mit Hypothesen. Letztere öffnen den Weg zu Forschungen und Experimenten. Aber Versuche am Menschen müssen streng an dem Grundsatze: primum non nocere festhalten.

Mit Berücksichtigung aller dieser Umstände wird in unserem Sanatorium die spezifische Therapie verwendet. - Wenn wir uns des $\mathrm{TB}_{\mathrm{K}}$ bedienen, so geschieht dies auf Grund der Empirie. Denn wir sahen gute Resultate von $\mathrm{TB}_{\mathrm{K}}$ in der Berner Klinik unter Leitung Sahlis. Indem wir im allgemeinen nach seiner Methode verfahren, haben wir, wie aus dem zweiten Teile unserer Arbeit ersichtlich, keine Schädigung der Gesundheit unserer Kranken zu verzeichnen.

Zakopane, Ende November 1909.

\section{Bibliographie.}

\section{Teil.}

1. Bandelier, Stand der spezif. Behandlung der Tuberkulose. IV. Versammlung der Tuberkulose-Ärzte 1907. 
2. Bandelier und Roepke, Lehrbuch der spezif. Diagnostik und Therapie der Tuberkulose. 1909. Würzburg, Curt Kabitzsch.

3. S. Bernheim et P. Barbier, Valeur thèrapeutique des Tuberculines. Zeitschrift f. Tuberk. Bd. 13.

4. Bau med. Wochenschr. 1909. Nr. 24.

5. Derselbe, Über Immunitätsvorgänge bei der Tuberkulose. Beitr. z. Klin. der Tub. Bd. XIII.

6. Derselbe, Über die Bedeutung und die Spezifität der komplementbindenden Antikörper bei Tuberkulose etc. Münch. med. Wochenschr. 1908. Nr. 44.

7. P. B erm b a ch, Blatuntersuchungen auf Tuberkulose-Immunkörper. Zeitschr. f. Tuberkulose. Bd. XIII.

8. A. Besredka, De l'anaphylaxie sérique expérimentale. Bull. de l'Inst. Pasteur 1908. Nr. 19-21.

9. Derselbe, Du traitement preventif de l'anaphylaxie. Ibid. 1909. Nr. 17.

10. Böhme, Über Tuberkulose-Immunopsonin. Münch. med. Wochenschr. 1909. Nr. 22 u. 23.

11. Carriére (Berne), La tuberculose et l'armement antituberculeux en Suisse. Sep-Abdruck aus Tuberculosis 1905.

12. Christian und Rosenblatt, Untersuchungen über Tuberkulose-Antikörper und Immunität. Münch. med. Woch, 1908. Nr. 39.

13. S. Cohn, Über die durch Komplementbildung nachweisbaren T'uberkulose. Antikörper im Blute von Phthisikern. Beitr. z. Klin. der Tub. Bd. XI.

14. Daels, Zur Kenntnis der kutanen Impfpapel bei der Tuberkulose-Diagnose nach v. Pirquet. Med. Klin. 1908. Nr. 2.

15. Denys, Le boullon filtré. Paris 1905.

16. Eber, Die Tuberkuloseschutz- und Heilimpfung der Rinder nach Prof. Dr. He ymans. Zentralbl. f. Bakt. Bd. XLII. Nr. 9/10. 1908.

17. Engel und Bauer, Über die Bedeutung und die Spezifität der ,komplementbindenden Antikörper" bei 'Tuberkulose und deren Beziehungen zu Heilungsvorgängen. Münch. med. Wochenschr. 1908. Nr. 44.

18. U. Friedemann, Über passive Überempfindlichkeit. Münch. med. Wochenschrift 1907. Nr. 49.

19. Gebhard (Lübeck), Die Dauer des Erfolges der von der Landesversicherungsanstalt der Hansestädte bei Lungenschwindsüchtigen eingeleiteten Ireilverfahrens. Zeitschr. f. Tub. Bd. 8. Heft 2.

20. Goetsch, Über die Behandlung der Lungentuberkulose mit Tuberkulin. Deutsche med. Wochenschr. Nr. 25. 1901.

21. H a m burger, Über Tuberkuloseimmunität. Beitr. z. Klin. der Tub. Bd. XII.

22. Derselbe, Über Tuberkuloseimmunität. Münch. med. Wochenschr. 1908. Nr. 42.

23. Derselbe, Über die Wirkung des Alttuberkulins auf den tuberkulosefreien Menschen. Münch. med. Wochenschr. 1908. Nr. 23.

24. Haentjens, Die Ursachen der relativen angeborenen Immunität des Hundes gegen Tuberkelbazillen. Zeitschr. f. Tub. Bd. XI. Heft 3.

25. Derselbe, Tuberkeltoxin-Studien. Ibid. Bd. XI. Heft 4.

26. Humbert, Quels résultats pouvons-nous obtenir avec la tuberculine Beraneck. Revue méd. de la Suisse-Romande Nr. 10. 1906.

27. Hamel, Deutsche Heilstätten für Lungenkranke. Tuberkulose-Arbeiten aus dem Kaiserlichen Gesundheitsamte. Heft 8. Berlin 1908. 
28. Klimmer, Tuberkuloseschutzimpfung der Rinder mit nichtinfektiösen Impfstoffen. Zentralbl. f. Bakt. (Referate Bd. XLIII. 1909.

29. F. Klemperer, Über die Tuberkulinbehandlung der Lungentuberkulose. Therapie der Gegenwart. Heft I und II, 1909.

30. Köh ler, VII. Jahresbericht der Heilstätte Holsterhausen. J. 1908.

31. Derselbe, Die Dauererfolge in der Behandlung Lungentuberkulöser in den deutschen Heilstätten. Tuberkulosis. Nr. 7. 1908.

32. Derselbe, Statistische Beiträge zur Frage der Kurerfolge Lungentuberkulöser in den Heilstätten. Deutsche med. Woche. Nr. 25. 1909.

33. Derselbe, Neue Dauererfolgstatistik der Heilstätte Holsterbausen. Tuberkulosis Nr. 2. 1909.

34. Link, Über Hautreaktionen bei Impfungen mit abgetöteten Typhus-Paratyphus-Bazillen und Kolibazillen. Münch. med. Wochenschr. 1908. Nr. 14.

35. Landmann, Über Tierversuche mit dem Spenglerschen TuberkuloseImmuukörper (J. K.) Berl. klin. Wochenschr. 1908. Nr. 45.

36. L ỉ d ke, Tuberkulin und Antituberkulin. Münch. med. Wochenschr. 1908. Nr. 15 u. 16.

37. Me issen, Bericbt über 208, seit 3-11 Jahren geheilt gebliebene Fälle von Lungentuberkulose. Zeitschr. f. Tub. Bd. 4. Heft 2.

38. Moeller, Ärztlicher Jahresbericht der Vereinsheilstätte bei Belzig für das Jahr 1903. Zeitsehr. f. T'ub. Bd. 5. Heft 5.

39. P. Th. M üller, Vorlesungen über Infektion und Immunität. G. Fischer. Jena. 1909.

40. Nowak, Sprawozdanie C. K. Tow. Roln. Krakowskiego 1908.

40a. Derselbe, Bericht der K. K. Krakauer Ackerbau-Gesellschaft fïr das Jahr 1908.

41. v. Pirquet, Klinische Studien über Vakzination. Wien 1907.

42. v. Pirquet und B. Schick, Die Serumkrankheit. Wien 1905.

43. Pickert, Über natürliche Tuberkulinresistenz. Deutsche med. Wochenschr. 1909. Nr. 23.

44. Derselbe, Über das gesetzmässige Auftreten von Tuberkulin-Antikörpern im Laufe der spezifischen Behandlung und seine Bedeutung für die Therapie. Deutscle med. Wochenschr. 1909. Nr. 38.

45. Pickert und Loewenstein, Eine neue Methode zur Prüfung der Tuberkulinimmunität. Deutsche med. Wochenschr. 1908. Nr. 52.

46. Kénon, Les indications de la tuberculine dans la phtisiothèrapie. Journal des Praticiens Nr. 12. 1909.

47. Reiche, Zur Kritik der Erfolge der Heilstättenbehandlung Lungenschwindsüchtiger. Zeitschr. f. Tub. Bd. 2. Heft 5.

48. Derselbe, Die Erfolge der Hailstättenkuren bei Lungenschwindsüchtigen. Münch. med. Wochenschr. Nr. 15. 1905.

49. Roepke, Ergebnisse der Tuberkulose-Immunblut-(I. K.) Behandlung. Deutsch. med. Wochenschr. 1909. Nr. 42.

50. Rothschild, Neue Gesichtspunkte in der Tuberkulintherapie. Beitr. z. Klin. der Tub. Bd. X.

51. Derselbe, Über Autotuberkuline. Zeitschr. f. Tuberkulose. Bd. XII.

52. Derselbe, Über Mischtuberkulin. Deutsche med. Wochenschr. 1909. Nr. 21.

53. Paul H. Römer, Spezifische Überempfindlichkeit und Tuberkuloseimmunität. Beitr. z. Klin. der Tub. Bd. XI.

54. Derselbe, Weitere Versuche über Immunität gegen Tuberkulose durch Tuberkulose etc. Beitr. z. Klin. Bd. XIII. 
55. Paul H. Römer, Über experimentelle kavernöse Lungentuberkulose. Berl. klin. Wochenschr. Nr. 18. 1909.

56. v. Ruck, Erfahrungen mit Tuberkulin und mit anderen Produkten des Tuberkelbazillus etc. Zeitschr. f. Tub. Bd. XI.

57. Ruge, Dauererfolge nach 10 Jahren bei Lungentuberkulose im Hochgebirge (aus dem Sanatorium Arosa). Zeitschr. f. Tub. Bd. 15. Heft 2.

57a. C. Saugman (Dänisch), „Mitteilungen vom Veljefjord Sanatorium" Kopenhagen 1909.

58. Schick, Katanreaktion bei Impfung mit Diphtherietoxin. Münch. med. Wochenschr. 1908. Nr. 10.

59. Schröder, Über das Vorkommen von Perlsuchtbazillen im Sputum der Phthisiker und ihre Bedeutung für die Therapie der chronischen Lungentuberkulose. Beitr. z. Klin. der Tub. Bd. XI.

60. Derselbe, Über die Rolle der Milz als Schutzorgan gegen TuberkuloseInfektion. Beitr. z. Klin. der Tub. Bd. XII.

61. Derselbe, Über die Dauer der Kur in den Heilstätten für Lungenkranke und deren Bedeutung im allgemeinen. IV. Versamml. der Tuberkulose-Ärzte 1907.

62. C. Spengler, Tuberkulose-Immunblut, Tuberkulose-Immunität und Taberkulose-Immunblut- (I.K.) Behandlung. Deutsche med. Wochensehr. 1908. Nr. 38.

63. Stephani et Gouraud, Tuberculinisation progressive par la tuberculine Denys. Congrès français de médecine 9e Sessior 1907.

64. Stephani, Indications pour l'emploi du serum antituberculeux $d u$ Dr. Marmorek. Congrès franç. de med. 10 session 1908.

65. Schnöller, Theoretisches und Praktisches ïber Inimunisierung gegen Tuberkulose ete. J. Schmidt-Strassburg. 1909.

66. Turba n, Beiträge zur Kenntnis der Lungentuberkulose. Wiesbaden 1899.

67. Turnau Laura, Statistik der Dauererfolge aus der Bernischen Heilstätte für Tuberkulose Heiligenschwendi bei Thun. Zeitschr. f. Tub. Bd. 15. Heft 1.

68. Weicker, Statistik über die Dauererfolye der von 1895-1900 entlassenen 3299 Personen. Beiträge zur Frage der Volksheilstätten. VIII. 1903.

69. Weicker und Bandelier, „Über I. K.“ Deutsche med. Wach. 1909. Nr. 42.

70. Wolff-Eisnor, Untersuchungen über einige Immunitätsfragen. Berl. klin. Wochenschr. 1904. Nr. 42 u. 44.

71. Derselbe, Typhustoxin, Typhusantitoxin und Typhusendotoxin. Die Beziehungen zwischen Überempfindlichkeit und Immunität. Berl. klin. Wochenschrift 1907. Nr. 38 .

72. Derselbe, Die prognostische Bedeutung der konjunktivalen und kutanen Tuberkulinreaktion. Berl. klin. Wochensehr. 1908. Nr. 2.

73. Derselbe, Über Versuche mit verschiedenen Tuberkelbazillenderivaten. Berl. klin. Wochenschr. Nr. 30 und 31 .

74. Derselbe, Die Endotoxinlehre. (Antwort auf den Artikel von E. von Pirquet etc.). Münch. med. Wochenschr. 1906. Nr. 5.

75. Derselbe, Die neue Krklärung der Tuberkulinwirkung. (Entgegnung auf die Arbeit von Zieler.) Münch. med. Wochenschr. 1908. Nr. 35.

76 Verselbe, Frühdiagnose und Tuberkulose-Immunität. 2. Auflage 1909 (Curt Kabitzsch).

77. Yamanouchi, Über die Anwendung der Anapbylaxie zu diagnostischen Zwecken. Wien. klin. Wochenschr. 1908. Nr. 47. 